\title{
Hybrid blade and locking plate fixation for proximal humerus fractures: a comparative biomechanical analysis
}

\author{
Ali Jabran ${ }^{1}$, Chris Peach ${ }^{1,2}$, Zhenmin Zou ${ }^{1}$ and Lei Ren ${ }^{1 *}$
}

*Correspondence:
lei.ren@manchester.ac.uk
1 School of Mechanical,
Aerospace and Civil
Engineering, University
of Manchester, Sackville
Street, Manchester M13
9PL, UK
Full list of author information
is available at the end of the
article

${ }^{*}$ Correspondence: ei.ren@manchester.ac.uk Aerospace and Civil Engineering, University of Manchester, Sackville 9PL, UK is available at the end of the article

\begin{abstract}
Background: Open reduction and internal fixation of proximal humerus fractures can be difficult to achieve adequate, complication free results due to osteopenia of the proximal humerus and unstable fracture patterns. This study aimed to compare the biomechanical properties of a novel hybrid fixed angle blade plate (Fx plate) with an established fixed angle locking plate (PHILOS plate).

Methods: A two-part fracture was simulated in synthetic composite humeri by creating a transverse osteotomy and $10 \mathrm{~mm}$ fracture gap at the surgical neck. After treating the fractures with either an Fx plate or a PHILOS plate, humeral head was fixed and the shaft was displaced in a cantilever fashion. For elastic tests, loading was along the frontal and sagittal plane to achieve varus/valgus and extension/flexion, respectively. In plastic tests, loading was in a varus direction to determine the constructs' resistance to varus collapse.
\end{abstract}

Results: In elastic tests, both construct types had higher peak load and stiffness in extension/flexion than varus/valgus. Fx plate constructs were significantly stiffer than PHILOS constructs in varus/valgus (mean: 7.590/6.900 vs. 6.609/6.091 N/mm; $p<0.001$ for both) but significantly less stiff in extension/flexion (8.770/9.541 vs. 9.533/9.997 N/ $\mathrm{mm} ; \mathrm{p}<0.001$ for extension, $\mathrm{p}<0.05$ for flexion). In varus plastic tests, significantly higher peak loads were reported for Fx plate than PHILOS (134.391 vs. $115.531 \mathrm{~N}$; $p<0.001$ ).

Conclusions: In this fracture gap model, humeri implanted with a novel Fx plate provided higher varus/valgus stiffness but lower extension/flexion stiffness than a more traditional proximal humeral locking plate design (PHILOS).

Keywords: Biomechanical analysis, Proximal humerus fractures, Plate fixation, Blade plate, Locking plate

\section{Background}

Fractures of proximal humerus are the third most common fractures of the human body, representing $5 \%$ of all fractures in all age groups $[1,2]$. They are also the third most common fractures in patients over the age of 65 years and are mostly linked to osteoporosis [3]. The majority (85\%) of proximal humerus fractures are minimally displaced and can be treated with good functional outcomes non-operatively [4-9]. Management of 
severely displaced fractures such as three- and four-part fractures remains a surgical challenge due to poor bone quality, forces from the rotator cuff and the increased risk of avascular necrosis caused by humeral head devascularisation. Managing these fractures conservatively lead to poor outcomes, mainly secondary to bony deformity and stiffness $[9,10]$. Due to conflicting evidence, controversy still lies around whether an operative or a non-operative approach leads to the best outcomes for patients. One possible reason for the observed increase in the incidence of open reduction and internal fixation procedures could be due to design innovation of fracture implants. Several design philosophies and technologies have emerged including locking and, more recently, hybrid blade plate designs.

Locking plates rely on screws being able to lock into the threaded plate, resulting in a fixed-angle fixation. This construct aims to improve fracture stability and is reliant on the bone-screw interface instead of the bone-plate interface. In the clinical setting, however, their performance varies as several implant-specific problems have arisen. Clinical studies report a high rate of complications such as varus deformity, screw penetration into the joint, cut-out, need for revision surgery, malreduction, avascular necrosis and tuberosity displacement $[1,11-16]$.

Blade plates allow insertion of the blade often at the humeral head's medial calcar region. Blades are inserted to further buttress the bone-plate construct by supporting the humeral head from varus collapse. The fundamental reason behind using a blade instead of the screw is that the former provides the construct with a larger surface area than the latter. Theoretically, this is beneficial not only for support in fracture fixation but also for avoiding cut-out, a common complication associated with screw-based fixations. In general, blade plates have become less popular as they were unable to counter the large coronal plane bending moment. When a blade plate is used, it appears to be associated with poor clinical outcomes [17]. Results from the clinical and biomechanical studies of blade plates are also found to vary considerably, making it difficult to derive a generalised conclusion [18-21].

Merging the two types of plates, a concept of hybrid plate has recently emerged, offering implantation of both blades and locking screws to a single plate with the aim of reaping the benefits of both and compensate for each other's disadvantages. Thus, the purpose of this study was to compare, in a synthetic bone model, the biomechanical stability of two-part fractures of the surgical neck treated with the novel hybrid fixed angle blade plate with those treated with a fixed angle locking plate.

Our hypothesis was that the new hybrid blade plate and locking fixation construct would exhibit superior biomechanical performance compared to the standard locking plate fixation.

\section{Methods}

\section{Specimen preparation}

Ten left synthetic humeri (model 1028; Pacific Research Laboratories, Vashon, WA, USA) were obtained. To allow secure clamping of the humeri during the tests, they were potted in cement blocks. To achieve this, each humeral head was placed inside a $10 \mathrm{~cm}$ cubic mould such that the section from the head apex and $4 \mathrm{~cm}$ distal was inside the mould. Sides of the mould were parallel to the sagittal and the frontal plane. Once the 
humerus was in the correct place, a mixture containing general purpose (Portland limestone) cement, rapid mix cement and water at a ratio of 4:1:2.5 by volume, was prepared and poured into the mould. Care was taken to ensure that the cement did not cover the region where the implant would be inserted. At least $48 \mathrm{~h}$ were required for a block to dry sufficiently and be ready for removal from the mould. Upon removal, a transverse cut was made $21 \mathrm{~cm}$ from humeral head apex to discard the distal end of the humerus.

Specimens were split into two groups of five; one group was implanted with a $90 \mathrm{~mm}$ PHILOS plate (Synthes, Paoli, Pennsylvania, USA) and the other with an $80 \mathrm{~mm}$ Equinoxe Fx plate (Exactech, Gainsville, FL). As per manufacturers' guidelines, plates were implanted approximately 30 and $12 \mathrm{~mm}$ distal to the superior greater tuberosity, respectively. All implantations were performed using the surgical instruments provided by manufacturers by a senior orthopaedic consultant surgeon.

For PHILOS, all but the screw above the two calcar screws (Fig. 1a, screw hole 7) were filled using $3.8 \mathrm{~mm}$ locking screws. A pair of $40 \mathrm{~mm}$ screws were inserted in the most proximal screw holes ( 1 and 2) followed by a 42 and a $50 \mathrm{~mm}$ screw at screw hole 3 and 4. Screw holes 5 and 6 were filled with screws of length $40 \mathrm{~mm}$ while screw holes 8 and 9 were with $50 \mathrm{~mm}$ ones. Moving distally, the three shaft screws were 32,30 and $30 \mathrm{~mm}$ long.

Likewise, for Fx, all but the calcar screws themselves (Fig. 1b, screw holes 6 and 7) were filled. There, a $45-\mathrm{mm}$ blade was inserted instead. A $6.5 \mathrm{~mm}$ diameter locking screw of length $50 \mathrm{~mm}$ was inserted into screw hole 5 while other screws were $3.8 \mathrm{~mm}$. Screw holes 1-2 and 3-4 were treated with pairs of 44 and $23 \mathrm{~mm}$ locking screws. $26 \mathrm{~mm}$ cortical locking screws were inserted into screw holes 8 and 10 while a $32 \mathrm{~mm}$ non-locking compression screw was inserted in screw hole 9.

These lengths were determined in pilot experiments by using the depth gauge until resistance from subchondral bone was felt, allowing the maximum purchase. Upon implantation, a two-part, unstable fracture pattern was simulated, by creating a transverse osteotomy at the surgical neck ( $50 \mathrm{~mm}$ from the humeral head apex) with a $10-\mathrm{mm}$ fracture gap.

\section{Biomechanical testing}

For testing the specimens were placed in a uniaxial Instron 4500 material testing machine (Instron, Canton, MA, USA), with the cement block clamped to machine's base and shaft perpendicular to a semi-cylindrical loader (Fig. 2).

First, elastic testing was performed, for which each specimen was subjected to five trials of varus, valgus, extension and flexion bending. This was achieved by turning the cement block to the corresponding planes. For each of the four directions, loads were applied $12 \mathrm{~cm}$ distal to the fracture site in a cantilever fashion under displacement control at a rate of $1 \mathrm{~mm} / \mathrm{s}$ up to $5 \mathrm{~mm}$ of actuator displacement. Based on pilot experiments, this 5-mm displacement was found to be well within the linear elastic region of both plate constructs for $1 \mathrm{~mm} / \mathrm{s}$ displacement rate. From the load-displacement data recorded, load at $5 \mathrm{~mm}$ and the stiffness ( $\mathrm{K}$, gradient of the linear portion of the forcedisplacement plot) were calculated for each specimen. From these, the mean value of stiffness $(\mathrm{K})$ and load at $5 \mathrm{~mm}\left(\mathrm{~F}_{5}\right)$ for five specimens were calculated in each construct group. 


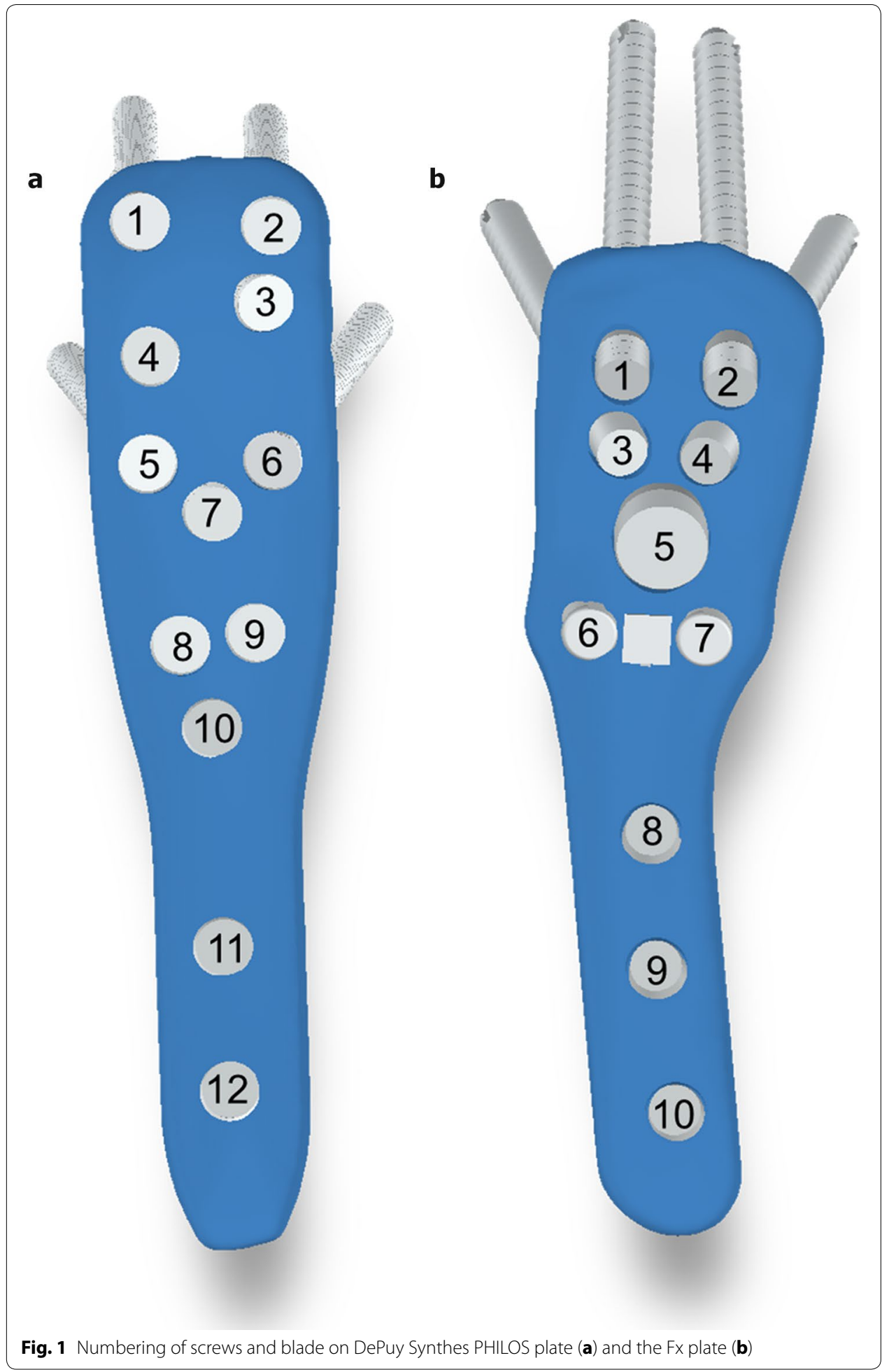

In order to investigate constructs' resistance to varus collapse, it was important to subject them to varus displacements well within the constructs' plastic region. Therefore, after completion of the elastic testing in the four load directions, specimens were set 


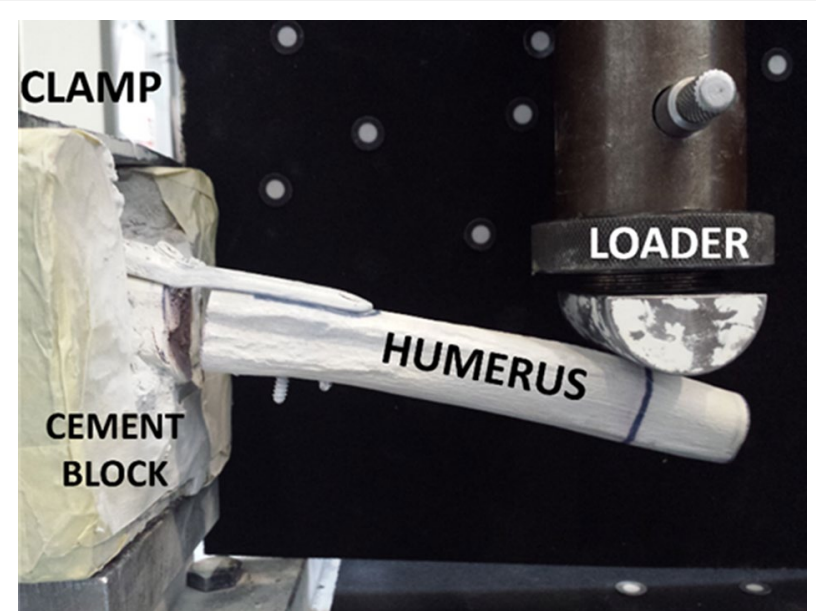

Fig. 2 Experimental setup for performing bending tests, shown with Fx plate in varus

in the varus position to begin plastic tests where they were loaded at $0.05 \mathrm{~mm} / \mathrm{s}$ from 0 to $15 \mathrm{~mm}$ displacement and the crosshead was arrested for $8 \mathrm{~min}$. Then, at the same displacement rate, specimens were loaded from 15 to $30 \mathrm{~mm}$ displacement, well within their plastic region. Load at $15 \mathrm{~mm}$ before $\left(\mathrm{F}_{15 \mathrm{a}}\right)$ and after $\left(\mathrm{F}_{15 \mathrm{~b}}\right)$ the eight-minute intermission and load at $30 \mathrm{~mm}$ (F30) were determined from the load-displacement data. Pilot experiments revealed that at $0.05 \mathrm{~mm} / \mathrm{s}$ displacement rate, $30 \mathrm{~mm}$ displacement was sufficient to cause plastic deformation of both plate constructs.

\section{Statistical analysis}

SPSS 22.0 statistical analysis software (IBM, NY, USA) was used to perform statistical analysis of the obtained data. Statistical significance of the effect of different plates on constructs' stiffness and load values was determined via a linear mixed model approach by taking intra- and inter-subject variability into account. In the analysis, the fixed effect was the plate type while the specimens and trials were the random effects. The dependent variables were $K$ and $F_{5}$ for elastic tests and $F_{15 a}, F_{15 b}$ and $F_{30}$ for plastic tests. Differences between each pair were tested using Fisher's least significant difference (LSD) multiple comparison based on the least-squared means. The statistical significance was set at $\mathrm{p}<0.05$.

\section{Results}

No implant failure or cut-out was noted for any of the construct groups in either elastic or plastic test. In the elastic tests, for both fixation constructs, the directions could be ranked in the following order of decreasing construct stiffness: flexion, extension, varus and valgus (Fig. 3). The PHILOS plate constructs demonstrated significantly higher stiffness than Fx constructs in extension $(\mathrm{p}<0.001)$ and flexion $(\mathrm{p}=0.025)$ with mean stiffness values 8.69 and $4.77 \%$ higher (Table 1). This is the conversely, the Fx plate constructs demonstrated significantly higher stiffness than PHILOS constructs in varus and valgus ( $\mathrm{p}<0.001$ for both), with mean stiffness values 14.85 and $13.27 \%$ higher, respectively. Expectedly, these trends were consistent across $F_{5}$ values obtained (Fig. 4). 


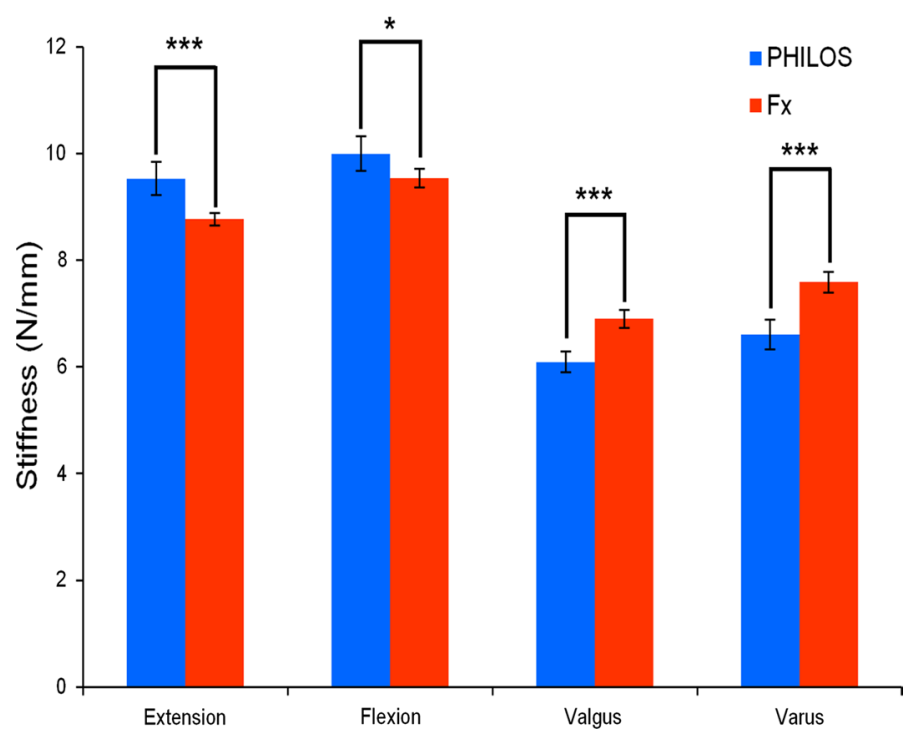

Fig. 3 Mean stiffness (S) for PHILOS and Fx plate constructs during elastic loading of $5 \mathrm{~mm}$ cantilever displacement in extension, flexion, valgus and varus directions. For each direction, stiffness is presented as the mean for five specimens ( 25 trials) in each construct group. A single asterisk $\left(^{*}\right)$ indicates $p \leq 0.05$; and triple asterisks $\left(^{* *}\right)$ indicate $p \leq 0.001$

Table 1 Mean stiffness (K) and load values (F) for all specimens of both plate constructs in each loading direction with their respective standard deviations (S.D.) and $p$ values from pairwise statistical comparisons

\begin{tabular}{|c|c|c|c|}
\hline Loading direction/variable & Fx plate construct \pm S.D. & PHILOS plate construct \pm S.D. & $p$ value \\
\hline \multicolumn{4}{|l|}{ Extension } \\
\hline $\mathrm{K}(\mathrm{N} / \mathrm{mm})$ & $8.770 \pm 0.156$ & $9.533 \pm 0.286$ & $<0.001$ \\
\hline $\mathrm{F}_{5}(\mathrm{~N})$ & $43.979 \pm 0.596$ & $47.749 \pm 1.510$ & $<0.001$ \\
\hline \multicolumn{4}{|l|}{ Flexion } \\
\hline $\mathrm{K}(\mathrm{N} / \mathrm{mm})$ & $9.541 \pm 0.221$ & $9.997 \pm 0.298$ & $<0.05$ \\
\hline $\mathrm{F}_{5}(\mathrm{~N})$ & $47.711 \pm 0.775$ & $49.981 \pm 1.569$ & $<0.05$ \\
\hline \multicolumn{4}{|l|}{ Valgus } \\
\hline $\mathrm{K}(\mathrm{N} / \mathrm{mm})$ & $6.900 \pm 0.200$ & $6.091 \pm 0.181$ & $<0.001$ \\
\hline $\mathrm{F}_{5}(\mathrm{~N})$ & $35.131 \pm 0.617$ & $29.746 \pm 0.815$ & $<0.001$ \\
\hline \multicolumn{4}{|l|}{ Varus } \\
\hline $\mathrm{K}(\mathrm{N} / \mathrm{mm})$ & $7.590 \pm 0.196$ & $6.609 \pm 0.256$ & $<0.001$ \\
\hline $\mathrm{F}_{5}(\mathrm{~N})$ & $37.792 \pm 0.990$ & $32.561 \pm 1.075$ & $<0.001$ \\
\hline $\mathrm{F}_{15 \mathrm{a}}(\mathrm{N})$ & $84.470 \pm 1.547$ & $75.590 \pm 3.049$ & $<0.001$ \\
\hline$F_{15 b}(N)$ & $79.304 \pm 2.507$ & $71.558 \pm 3.303$ & $<0.01$ \\
\hline $\mathrm{F}_{30}(\mathrm{~N})$ & $134.391 \pm 3.574$ & $115.531 \pm 6.336$ & $<0.001$ \\
\hline
\end{tabular}

$\mathrm{K}$ and $\mathrm{F}_{5}$ are the stiffness and peak load values during elastic tests, respectively. $\mathrm{F}_{15 \mathrm{a}}$ and $\mathrm{F}_{15 \mathrm{~b}}$ are loads at $15 \mathrm{~mm}$ before and after eight-minute intermission and $\mathrm{F}_{30}$ is the load at $30 \mathrm{~mm}$

In plastic varus failure tests, Fx plate constructs' load at $30 \mathrm{~mm}$ were significantly higher $(\mathrm{p}<0.001)$ than those of PHILOS, with former's mean values being $134.39 \mathrm{~N}$ compared to latter's only $115.53 \mathrm{~N}$, an increase by $16.32 \%$ (Fig. 5). Both construct groups were found to retain their structural integrity as there was no observation of screw 


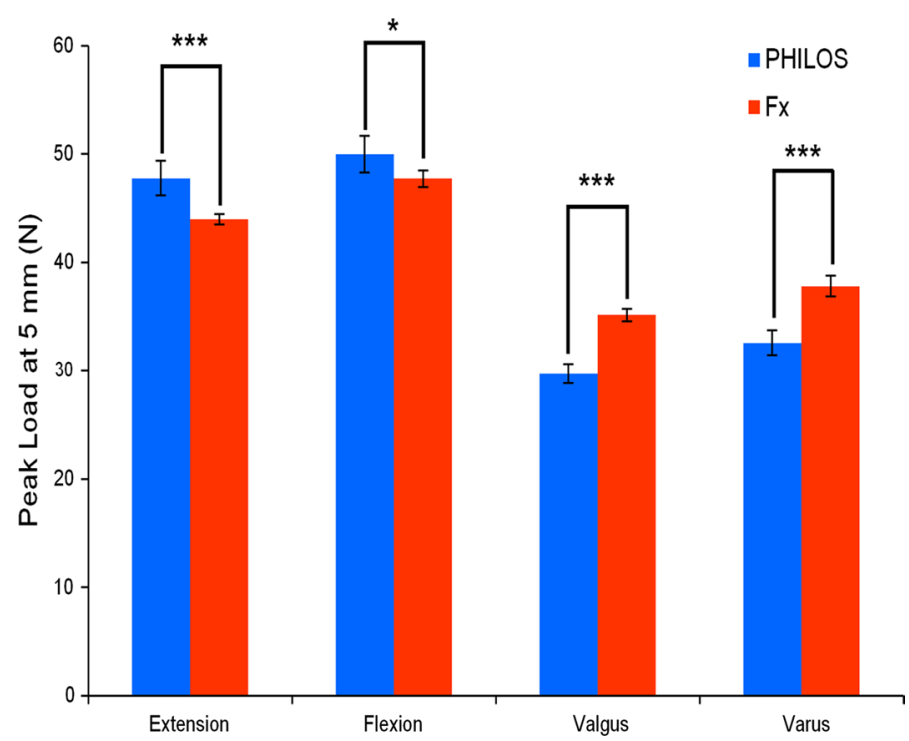

Fig. 4 Mean peak load $\left(F_{5}\right)$ for PHILOS and Fx plate constructs during elastic loading of $5 \mathrm{~mm}$ cantilever displacement in extension, flexion, valgus and varus directions. For each direction, peak load is presented as the mean for five specimens ( 25 trials) in each construct group. A single asterisk $\left(^{*}\right)$ indicates $p \leq 0.05$; and triple asterisks $\left.{ }^{* * *}\right)$ indicate $p \leq 0.001$

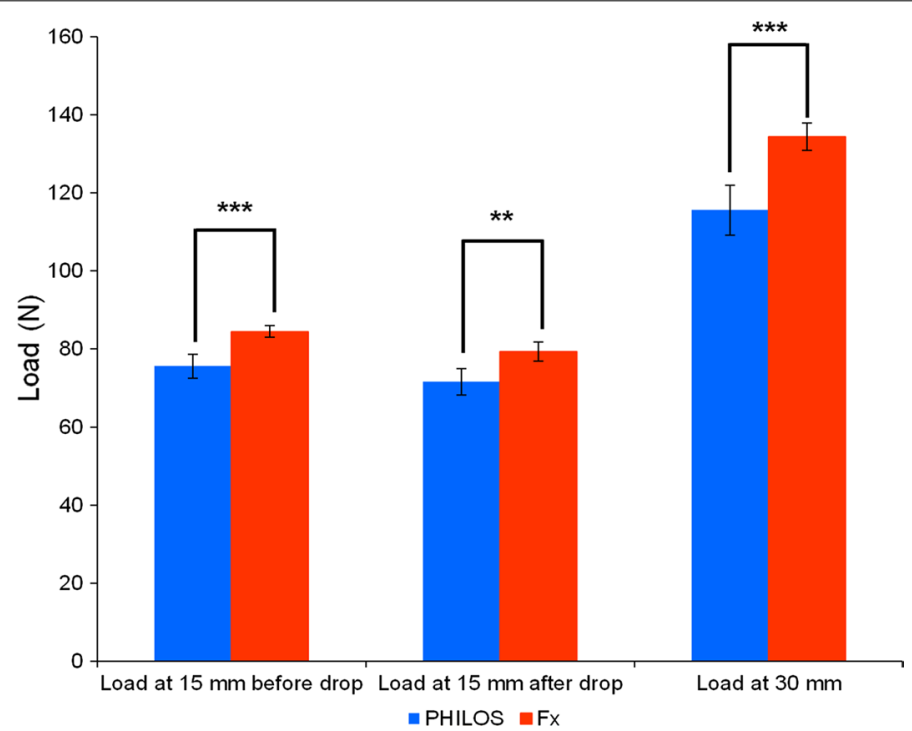

Fig. 5 Mean load for PHILOS and Fx plate constructs during plastic loading at $15 \mathrm{~mm}$ displacement before $\left(F_{15 a}\right)$ and after $\left(F_{15 b}\right)$ eight-minute intermission and at $30 \mathrm{~mm}$ displacement $\left(F_{30}\right)$. Load is presented as the mean for five specimens ( 5 trials) in each construct group. A single asterisk $\left(^{*}\right)$ indicates $p \leq 0.05$; and double asterisks $\left.{ }^{* *}\right)$ indicate $p \leq 0.01$

pull-out. Temporal stress decay was observed during the eight-minute intermission, owing to stress relaxation, a phenomenon commonly exhibited by viscoelastic materials such as polyurethane (a primary constituent of synthetic humeri) when under constant strain (Fig. 6). As a result of stress relaxation, an approximately 4-5 $\mathrm{N}$ drop in load 


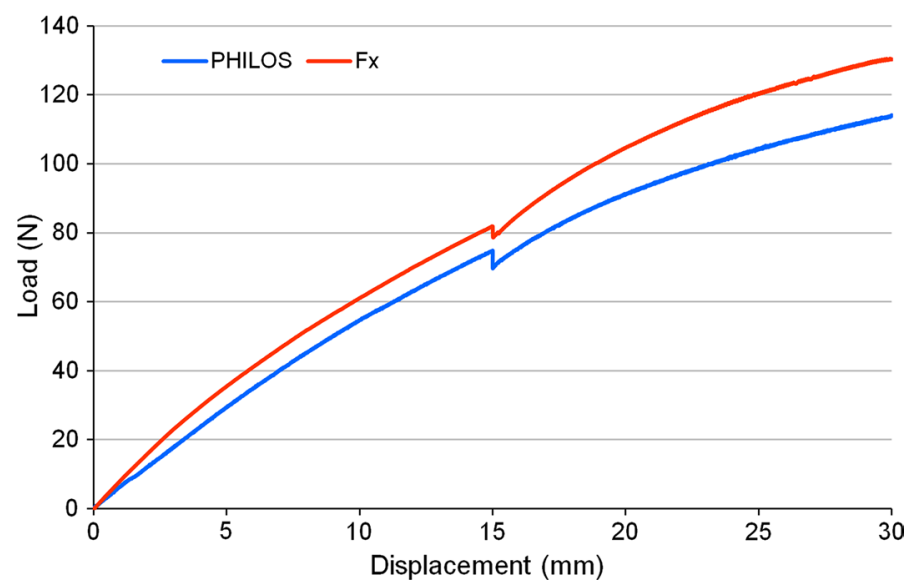

Fig. 6 Typical load-displacement curves at load point for PHILOS and Fx plate constructs during plastic loading. A drop of $4-5 \mathrm{~N}$ in load is noted at $15 \mathrm{~mm}$ displacement due to the stress relaxation of construct during the eight-minute intermission

(the difference between $\mathrm{F}_{15 \mathrm{~b}}$ and $\mathrm{F}_{15 \mathrm{a}}$ ) was recorded on the load-displacement plot at abscissa of $15 \mathrm{~mm}$.

\section{Discussion}

The PHILOS plate is one of the most widely studied proximal humerus fixation systems in biomechanical literature, introduced typically as the representative of the broad category of locking plates. On the contrary, to our knowledge, no such study exists for the Fx plate constructs yet or to compare the performance of this new concept of hybrid blade plates. In addition to being the first in vitro biomechanical study on hybrid blade plates, the current study has two novel contributions to the biomechanical literature.

One significant finding of the current study was that the Fx offered stiffer constructs in varus and valgus bending than the PHILOS plate. The implications of this finding are of key importance given that the varus malreduction and displacement has been reported to be one of the most common complications associated with locking plates [22-24]. By exhibiting higher stiffness in varus/valgus, Fx plate appears to have beneficial characteristics that could reduce this severe complication for patients. One possible reason is the position of the blade. The blade begins near the fracture gap and crosses the calcar region, a region critical for humeral head's stability against varus collapse [25, 26]. Its increased surface area might significantly improve the support in this important region. This finding is in contrast to the study by Siffri et al. which reported statistically similar varus bending stiffness between a locking plate and a traditional non-locking blade plate. Also, Gillespie et al. subjected cadaveric humeri to $20^{\circ}$ of abduction from vertical [27] and the mean stiffness value for non-locking blade plate was found to be $12 \%$ higher than locking plate but with no statistically significant difference.

The second significant finding of this study was that the PHILOS plate was stiffer than the Fx plate in extension and flexion bending, thereby only partially confirming our hypothesis. Everyday movements of the glenohumeral joint and specifically the humerus are complex, involving a combination of varus, valgus, extension and flexion bending, as 
well as torsion and compression. When comparing the performance of bone plate construct, extension and flexion bending stiffness should also be accounted, despite the high prevalence of varus failure. In this regard, the stiffer constructs achieved by PHILOS plate under extension and flexion bending is noteworthy, since in everyday movements such as arm extension and flexion, the stability in these two directions also contribute to the potential failure of the bone-plate construct. The difference in the performance of the two plates may also be due to their screw hole designs. A non-locking screw had to be used in Fx plate's hole 9 since the plate does not allow insertion of a locking screw there. In PHILOS, all screws were locking and this may have potentially affected the relative stiffness of the two plate constructs.

Based on previous biomechanical comparisons between locking plates and non-locking blade plates, the locking plate may also be stiffer than the Fx plate during torsion tests. Weinstein et al. [21], for example, compared the torsional performance of a locking plate with an angled blade plate for treatment of three-part fractures on cadaveric humeri. Mean initial torsional stiffness was reported to be significantly higher for the locking plate than a blade plate. Siffri et al. [28] seem to provide ample support to this conclusion. Like Weinstein et al. they also applied torsional loading and reported significantly less fixation loosening for locking plate than the blade plate, at least for cadaveric humeri.

In elastic tests, the 5-mm displacement limit was set purely to keep the specimens well within their elastic region, allowing testing in all four directions and subsequent plastic testing. Results from plastic testing show that the biomechanical superiority of the Fx plate constructs over PHILOS plate constructs under varus loading, in terms of construct peak loads and stiffness, holds true beyond the elastic region. Despite the drop in the load in the course of the eight-minute intermission, Fx specimens remained to be stronger than the PHILOS.

Cantilever loading has been used previously in the literature, often to achieve a bending moment of $0-7.5 \mathrm{Nm}$ at the fracture site [28-33]. Comparable bending loads were applied by Chow et al. and Weeks et al. who performed cantilever bending on the basis of a biomechanical study by Poppen and Walker, with the aim of replicating the supraspinatus forces on bone-plate constructs during the early stages of healing under shoulder immobilisation support [29, 32, 34]. Mechanically, this loading is comparable to humeral immobilisation followed by a varus force acting directly at the supraspinatus insertion site. A similar range of bending moments (at fracture site) was achieved in our study during elastic loading $(0-4.8 \mathrm{Nm})$. For the plastic loading, however, these bending moments reached up to approximately $17 \mathrm{Nm}$ for Fx plate constructs and $14 \mathrm{Nm}$ for PHILOS plate constructs. Despite these loadings, no implant failure was reported.

The choice for the use of synthetic humeri was based on a recent biomechanical study where the same polyurethane foam humeri as those used in this study were tested along with human cadaveric humeri [35]. In the study, the results for cadaveric specimen had large variations, due to their inherent biologic variability. Huff et al. were able to draw similar conclusions from the testing of cadaveric and synthetic specimens and recommended synthetic humeri for future studies.

A disadvantage of our experimental procedure, and in fact of most biomechanical studies in literature, is that the in vivo forces acting on the humerus are unlikely to be 
unidirectional. Human shoulder movement is extremely complex. Designing and conducting in vitro biomechanical tests that accurately simulate in vivo conditions of a joint with such a high degree of complexity as the glenohumeral joint is in itself a major challenge in the advancement of investigations into the treatment of proximal humerus fractures.

We approached this problem by loading the specimens along the two main anatomical planes and in the four directions sequentially, instead of simultaneously, to make the results simpler to interpret and yet clinically relevant. Nevertheless, caution should be exercised when extrapolating these experimental laboratory findings to the clinical situation.

One possible way to tackle this limitation is to load the humerus in the magnitude and direction of the resultant force of glenohumeral joint for a given shoulder movement which takes into consideration the muscles forces, bone-to-bone forces and connective tissue forces. Even then, however, there remains inaccuracy in loading conditions because the glenohumeral joint forces on their own do not fully depict the in vivo scenario. The humerus has insertion points for most shoulder muscles including the deltoid, infraspinatus, supraspinatus, subscapularis and pectoralis major muscles, all of which pull at a different region of the humerus at different stages of shoulder movements. More accurate simulation of in vivo conditions would be possible by first obtaining a cadaveric shoulder complex with muscles attached and then pulling individual muscles to create desired movements. This type of testing has already been conducted in the literature, notably by Voigt et al. and her colleagues [36-38]. They used a robotassisted shoulder simulator which allowed differentiated application of defined muscle forces (such as that of the rotator cuff muscles) along with their physiological lines of action and in proportion to their respective physiological cross-sectional areas. Studies such as these involve cadaveric humeri, thus the issue of inter-specimen variability have to be taken into consideration. In Voigt's et al. study, input values were from previous studies, however, measurement of in vivo biomechanical contribution of individual muscle during shoulder movement is challenging and is a hot topic in the literature [39-41].

\section{Conclusions}

This study was the first in vitro biomechanical comparison of hybrid blade plate and locking plate. It was found that while the hybrid plate demonstrates superior biomechanical characteristics in varus and valgus, it is inferior to the locking plate extension and flexion. Since the commonest mode of failure is varus collapse and subsequent screw cut out, this data suggests that the hybrid blade plate is better able to prevent them. However, everyday movements are complex and bone-plate construct's stability in all four directions can contribute to fixation failure. Thus, further clinical studies are required to investigate the implications of hybrid blade plate's inferior extension and flexion bending stiffness under more complex movements.

Authors' contributions

AJ conducted tests, performed data analysis and literature study and prepared manuscript. CP manuscript editing and discussion on the clinical aspects of the study. ZZ involved in design of the mechanical tests. LR overall supervision of study including mechanical testing design, as well as manuscript editing. All authors read and approved the final manuscript. 


\section{Author details}

${ }^{1}$ School of Mechanical, Aerospace and Civil Engineering, University of Manchester, Sackville Street, Manchester M13 9PL, UK. ${ }^{2}$ Department of Shoulder and Elbow Surgery, University Hospital of South Manchester, Southmoor Road, Wythenshawe, Manchester M23 9LT, UK.

\section{Acknowledgements}

None.

\section{Competing interests}

Dr. Chris Peach has a consultancy agreement with Exactech Inc. in relation to educational activity and not in relation to products in this article. All authors of this manuscript have no other affiliations with or involvement in any organization or entity with any financial interest (such as honoraria; educational grants; participation in speakers' bureaus; membership, employment, consultancies, stock ownership, or other equity interest; and expert testimony or patent-licensing arrangements), or non-financial interest (such as personal or professional relationships, affiliations, knowledge or beliefs) in the subject matter or materials discussed in this manuscript.

\section{Availability of data and materials}

All data generated or analysed during this study are included in this published article.

\section{Consent for publication}

Not applicable.

\section{Ethics approval and consent to participate}

Not applicable.

\section{Funding}

DePuy Synthes (West Chester, PA, USA) granted funding for the purchase of the PHILOS plates used in the biomechanical tests. DePuy Synthes (West Chester, PA, USA) was not involved in the design of the study and collection, analysis, and interpretation of data and in writing the manuscript.

\section{Publisher's Note}

Springer Nature remains neutral with regard to jurisdictional claims in published maps and institutional affiliations.

Received: 9 October 2017 Accepted: 17 January 2018

Published online: 25 January 2018

\section{References}

1. Kettler M, Biberthaler P, Braunstein V, Zeiler C, Kroetz M, Mutschler W. Treatment of proximal humeral fractures with the PHILOS angular stable plate. Presentation of 225 cases of dislocated fractures. Unfallchirurg. 2006;109:1032-40.

2. Baron JA, Barret JA, Karagas MR. The epidemiology of peripheral fractures. Bone. 1996;18:209S-13S.

3. Hagino H, Yamamoto K, Ohshiro H, Nakamura T, Kishimoto H, Nose T. Changing incidence of hip, distal radius, and proximal humerus fractures in Tottori Prefecture, Japan. Bone. 1999;24:265-70.

4. Helmy N, Hintermann B. New trends in the treatment of proximal humerus fractures. Clin Orthop Relat Res. 2006:442:100-8.

5. Bernstein J, Adler LM, Blank JE, Dalsey RM, Williams GR, lannotti JP. Evaluation of the Neer system of classification of proximal humeral fractures with computerized tomographic scans and plain radiographs. J Bone Jt Surg Am. 1996;78A:1371-5.

6. Court-Brown CM, McQueen MM. The impacted varus (A2.2) proximal humeral fracture: prediction of outcome and results of nonoperative treatment in 99 patients. Acta Orthop Scand. 2004;75:736-40.

7. Koval KJ, Gallagher MA, Marsicano JG, Cuomo F, McShinawy A, Zuckerman JD. Functional outcome after minimally displaced fractures of the proximal part of the humerus. J Bone Jt Surg Am. 1997;79A:203-7.

8. Lill H, Josten C. Conservative or operative treatment of numeral head fractures in the elderly? Chirurg. 2001;72:1224.

9. Neer CS 2nd. Displaced proximal humeral fractures. I. Classification and evaluation. J Bone Jt Surg Am. 1970;52:1077-89.

10. Leyshon RL. Closed treatment of fractures of the proximal humerus. Acta Orthop Scand. 1984;55:48-51.

11. Bjorkenheim JM, Pajarinen J, Savolainen V. Internal fixation of proximal humeral fractures with a locking compression plate: a retrospective evaluation of 72 patients followed for a minimum of 1 year. Acta Orthop Scand. 2004;75:741-5

12. Clavert $P$, Adam $P$, Bevort A, Bonnomet F, Kempf JF. Pitfalls and complications with locking plate for proximal humerus fracture. J Shoulder Elb Surg. 2010;19:489-94.

13. Fankhauser F, Boldin C, Schippinger G, Haunschmid C, Szyszkowitz R. A new locking plate for unstable fractures of the proximal humerus. Clin Orthop Relat Res. 2005:430:176-81.

14. Micic ID, Kim KC, Shin DJ, Shin SJ, Kim PT, Park IH, et al. Analysis of early failure of the locking compression plate in osteoporotic proximal humerus fractures. J Orthop Sci. 2009;14:596-601.

15. Owsley KC, Gorczyca JT. Displacement/screw cutout after open reduction and locked plate fixation of humeral fractures. J Bone Jt Surg. 2008;90:223-40.

16. Solberg BD, Moon CN, Franco DP, Paiement GD. Surgical treatment of three and four-part proximal humeral fractures. J Bone Jt Surg Am. 2009;91A:1689-97. 
17. Dheerendra SK, Khan WS, Barber J, Goddard NJ, Ahrens PM. Outcomes of locking plates in proximal humeral fractures: a systematic review. Shoulder Elb. 2011;3:74-84.

18. Kostler W, Strohm PC, Sudkamp NP. Proximal humerus fracture in advanced age. Treatment with fixed angle plate osteosynthesis. Chirurg. 2003;74:985-9.

19. Rehman S, Damron TA, Geel C. Humeral blade plate fixation of intercalary allografts and segmentally comminuted proximal humeral fractures: a preliminary report. Injury. 2000;31:783-8.

20. Sehr JR, Szabo RM. Semitubular blade plate for fixation in the proximal humerus. J Orthop Trauma. 1988;2:327-32.

21. Weinstein DM, Bratton DR, Ciccone WJ, Elias JJ. Locking plates improve torsional resistance in the stabilization of three-part proximal humeral fractures. J Shoulder Elb Surg. 2006;15:239-43.

22. Agudelo J, Schurmann M, Stahel P, Helwig P, Morgan SJ, Zechel W, et al. Analysis of efficacy and failure in proximal humerus fractures treated with locking plates. J Orthop Trauma. 2007:21:676-81.

23. Aksu N, Göğüş A, Kara AN, Işiklar ZU. Complications encountered in proximal humerus fractures treated with locking plate fixation. Acta Orthop Traumatol Turc. 2010;44:89-96.

24. Owsley KC, Gorczyca JT. Fracture displacement and screw cutout after open reduction and locked plate fixation of proximal humeral fractures. J Bone Jt Surg Am. 2008;90:233-40.

25. Gardner MJ, Weil Y, Barker JU, Kelly BT, Helfet DL, Lorich DG. The importance of medial support in locked plating of proximal humerus fractures. J Orthop Trauma. 2007;21:185-91.

26. Zhang L, Zheng JY, Wang WL, Lin GM, Huang YJ, Zheng J, et al. The clinical benefit of medial support screws in locking plating of proximal humerus fractures: a prospective randomized study. Int Orthop. 2011;35:1655-61.

27. Gillespie R, Ramachandran V. Biomechanical evaluation of 3-part proximal humerus fractures: a cadaveric study. Orthopedics. 2009;32:816.

28. Siffri PC, Peindl RD, Coley ER, Norton J, Connor PM, Kellam JE. Biomechanical analysis of blade plate versus locking plate fixation for a proximal humerus fracture: comparison using cadaveric and synthetic humeri. J Orthop Trauma. 2006;20:547-54

29. Chow RM, Begum F, Beaupre LA, Carey JP, Adeeb S, Bouliane MJ. Proximal humeral fracture fixation: locking plate construct \pm intramedullary fibular allograft. J Shoulder Elb Surg. 2012;21:894-901.

30. Edwards SL, Wilson NA, Zhang LQ, Flores S, Merk BR. Two-part surgical neck fractures of the proximal part of the humerus: a biomechanical evaluation of two fixation techniques. J Bone Jt Surg Am. 2006;88A:2258-64.

31. Fuchtmeier B, Hammer J, Nerlich M. Biomechanical behaviour of implant-reinforced subcapital humeral fractures. Zeitschrift Fur Met. 2002;93:819-24.

32. Weeks CA, Begum F, Beaupre LA, Carey JP, Adeeb S, Bouliane MJ. Locking plate fixation of proximal humeral fractures with impaction of the fracture site to restore medial column support: a biomechanical study. J Shoulder Elb Surg. 2013;22:1552-7.

33. Yamamoto N, Hongo M, Berglund LJ, Sperling JW, Cofield RH, An KN, et al. Biomechanical analysis of a novel locking plate with smooth pegs versus a conventional locking plate with threaded screws for proximal humerus fractures. J Shoulder Elb Surg. 2013;22:445-50.

34. Poppen N, Walker P. Forces at the glenohumeral joint in abduction. Clin Orthop Relat Res. 1978;135:165-70.

35. Huff LR, Taylor PA, Jani J, Owen JR, Wayne JS, Boardman ND. Proximal humeral fracture fixation: a biomechanical comparison of two constructs. J Shoulder Elb Surg. 2013;22:129-36.

36. Voigt C, Hurschler C, Althainz J, Vosshenrich R, Lill H. Effect of additive fiber cerclage of the rotator cuff in angle-stable plate-stabilized proximal humeral fractures. A biomechanical study of human shoulder specimens. Unfallchirurg. 2008:111:514-22.

37. Voigt C, Hurschler C, Rech L, Vosshenrich R, Lill H. Additive fiber-cerclages in proximal humeral fractures stabilized by locking plates No effect on fracture stabilization and rotator cuff function in human shoulder specimens. Acta Orthop. 2009;80:465-71.

38. Voigt C, Kreienborg S, Megatli O, Schulz AP, Lill H, Hurschler C. How does a varus deformity of the humeral head affect elevation forces and shoulder function? A biomechanical study with human shoulder specimens. J Orthop Trauma. 2011;25:399-405.

39. Halder AM, O'Driscoll SW, Heers G, Mura N, Zobitz ME, An KN, et al. Biomechanical comparison of effects of supraspinatus tendon detachments, tendon defects, and muscle retractions. J Bone Jt Surg Am. 2002;84-A:780-5.

40. Klages A, Hurschler C, Wulker N, Windhagen H. Muscle efficiency in total shoulder prosthesis implantation: dependence on position of the humeral head and rotator cuff function. Biomed Tech. 2001;46:241-6.

41. Veeger HE, Van der Helm FC, Van der Woude LH, Pronk GM, Rozendal RH. Inertia and muscle contraction parameters for musculoskeletal modelling of the shoulder mechanism. J Biomech. 1991;24:615-29. 